\title{
An Assessment of the Maintenance Management Effectiveness of Public Hospital Building Through Key Performance Indicators
}

\author{
Mardhiah Farhana Omara*, Fazdliel Aswad Ibrahim ${ }^{b}$, Wan Mohd Sabki Wan Omar ${ }^{a}$ \\ ${ }^{a}$ School of Environmental Engineering, Universiti Malaysia Perlis, 02600 UNIMAP kangar, Perlis, Malaysia \\ ${ }^{b}$ Faculty of Engineering Technology, Universiti Malaysia Perlis, 02100 UNIMAP, Perlis, Malaysia
}

*Corresponding author: mardhiahfarhana@studentmail.unimap.edu.my

\begin{abstract}
The importance of the facility maintenance management in the public hospital building has increased rapidly as many organisations aim to become world class. Maintenance management in hospital buildings recognized as a part of sustainability aspects in reaching optimum performances during at peak efficiency. Maintenance problem not only burden government and consumer but it also gives negative perception among foreigner that are made up investors and tourist from overseas, towards public of maintenance culture in this country. Therefore, aim of this study is to determine the key performance indicator (KPI) to seek the best strategy in maintenance management. A total of 32 questionnaires were distributed to maintenance manager. This survey covered 32 public hospitals including public hospitals in Northern region of Peninsular Malaysia. Majority of the respondent agrees that all the elements stated as a key performance indicators to maintenance management effectiveness. Ten factors were categorized as a key performance indicator to measure the effectiveness of maintenance management in the public hospital building. Result shows that monitoring and supervision, task planning and scheduling and computerized maintenance management system (CMMS) as a strong factors thus prove that maintenance manager as an important person and responsible to ensure the maintenance services operate with optimum performances. On the other hand, human resource management plays an important role to assist the maintenance team to achieving the objective and policy. Therefore, this discovery can evaluate implementation policy to increase further effectiveness of maintenance management level to any public hospital building.
\end{abstract}

Keywords: Effectiveness, maintenance management, key performance indicator, public hospital building

(C)2016 Penerbit UTM Press. All rights reserved

\subsection{INTRODUCTION}

Buildings have been considered as one of the most valuable assets of a nation to provide people with shelter and facilities for work and leisure. As time passes by, maintenance of buildings becomes an invaluable process in retaining the value and quality of a building. The maintenance of buildings plays an integral role in the whole design and construction process of buildings (Lam, Chan, \& Chan, 2010). Therefore, maintenance management is important for manufacturing plants, electricity generation plants and distribution systems, airlines operations, for facilities as buildings, roads and bridges. Lack of effective maintenance management will effect the performances of financial as stated by Shohet (2002). According to Cholasuke, Bhardwa and Antony (2004) maintenance management of hospital buildings is one of the more complex issues in the field of maintenance. The great complexity of hospitalisation buildings, the high criticality of hospital mechanical and electrical systems, and the shortage of maintenance budgets makes its challenge for maintenance team to complete their works. Moreover, the performance and operation of hospital buildings are affected by numerous factors. Among of the factors are age of buildings, building surroundings, managerial resources invested and labour sources for execution of maintenance with in-house provision or outsourcing.

The effectiveness of maintenance helps to increase the revenues by increasing the equipment performance and plant capacity. Effectiveness of buildings maintenance management and government asset is the important factor to ensure all government agencies was functioning to achieve of the respective objective for public interest country (Adenuga, 2012). For instance, Mydin (2014) mentioned every government buildings and physical facility need to be effectively and efficiently managed and maintained so that it ables to provide support services in achieving operational goals a government organization. Maintenance in government buildings are important to reduce disturbance or service interrupted when involved in government building. Failure to maintain a building can give bad performance and image to a government agency.

The Ministry of Health Malaysia (MOH) principally provides public healthcare in Malaysia and about 53 per cent of annual budget is allocated for health sector (Ahzahar, Karim, Hassan \& Eman, 2011). However, in 1997, the Government of Malaysia took the initiative to carry out a major privatization project for the provision, maintenance, and management of hospital support services (HSS) of public hospitals throughout the country (Manaf, 2005). As a result, the government has appointed concession companies (contractors) as a party to manage the maintenance management of public hospital. In Britain, for example, building maintenance activities account for 50 per cent of all annual construction activities. While, in Hong Kong, the gross value of general trades such as decoration, repair and maintenance, and construction work at minor work locations has increased over the past five years. In the USA, 35 per cent of the overall turnover in the construction sector consists of renovation and modification projects (Manaf, 2005). Therefore, Ali and Mohammad (2009). proposed governments all over the world have considerable expenditure directed toward maintenance and operation projects. The impact of building 
maintenance on quality and unit costs has to be understood. Many researchers are involved in the similar scenario of building maintenance. Essentially, the goal of the building maintenance organization especially in a hospital environment is to achieve zero defects in the hospital's physical operation.

The objective of the paper is to determine the key performance indicator of maintenance management of public hospital building. The findings are proposed as standard practice and procedures to government to measure the effectiveness of maintenance management of public hospital building. Overall in this research will give information and data that more systematic and scientific towards improvement of building maintenance management.

\subsection{THEORETICAL FOUNDATION OF THE STUDY}

Maintenance management encompasses many operations and functions and can be described as the effective and efficient. Use of resources to make sure that the process and its facilities are kept to comply standards requirement assigned by the users (Allen, 1993). Maintenance management in the public sector in Nigeria has suffered from a lack of funds for a long time.

According to Weber and Thomas (2005) building maintenance is gaining a central place in the construction activity worldwide. Wireman (2005) defined building maintenance management is a practical technique that is fragmentary and uncoordinated, reflecting the range of contractors which are involved in maintenance works. The quality and efficiency of a building maintenance management operation depend on how information on the condition of the building, the needs of the users, and the works carried out is collected and used.

In order to identify the effectiveness of maintenance management factors, key performance indicator is the best strategy to measure the performances of the building. Therefore, key performance indicators for each process are proposed to measure if requirements of each process are satisfied stated by Irajpour, ANajafabadi, Mahbod and Karimi (2014) this statement is in line with Ali and Mohammad (2009) which affirmed that key performance indicator is a fundamental principle in maintenance management. In this study, the building is refers to public hospital. As proposed by Ahzahar, Karim, Hassan \& Eman (2011), routine monitoring and supervision is one of the key elements to assess and identify the performance of organization in implementing plans, policies and procedures of maintenance management that relates to maintenance management. It will indicate the gap between the current performance and expected performance which could assist the organization to identify the opportunities for process improvement (Ahzahar, Karim, Hassan \& Eman, 2011). The proper supervision should be implemented in order to ensure that the maintenance work is performed in accordance to the work order conditions and based on standard maintenance procedures (Weber \& Thomas, 2005).

Besides that, routine monitoring and supervision need to be supported by task planning and working schedule. According to Coopers and Vaisnys, Contri, Rieg and Bieth (2016) maintenance plans and schedules help in scheduling maintenance work and allocating the resource for each work. However, task planning and scheduling need to be provided and managed by first line maintenance foreman or supervisor as well as responsible in providing the feedback to the maintenance planner to ensure that the proposed job plans are relevant, efficient and effective (Weber \& Thomas, 2005). The lack of planning and scheduling will definitely restrict a maintenance operation to meet its objective in delivering the optimum service as planned by the organization. As mentioned Wireman (2005) proper work planning can lead to high responsiveness, less unplanned work and less unplanned overtime with consequences of minimizing the overall maintenance cost.

In addition, Wireman (2005) suggested that information management system also a necessary elements of key performance indicators that provides the link between the current statuses of maintenance function in relation with the maintenance objective. Computerized maintenance management systems (CMMS) can be used to support the organization to automate the preventive planned maintenance (PPM) function and as an aid tool to control the maintenance inventories and material purchase for the purpose of maintenance works. CMMS is acknowledged as an effective tool that has capabilities of reporting the analysis that relates to overall maintenance management aspects quicker and accurate compared to than manual techniques. On the other hand, accessibility and accuracy of information can provide more reliable and decisions in proper maintenance work (Irajpour, ANajafabadi, Mahbod \& Karimi, 2014). Therefore, the above elements could be classified as individual factors because all the factors are concern about managerial aspect which influenced by a building maintenance leader.

The practice of maintenance approach is recognized as a factor that highly affect the maintenance performance. For instance, Wireman (2005) mentioned many organisations tend to adopt the proactive maintenance philosophies such as total productive maintenance (TPM) and reliability centered maintenance (RCM) since these approaches are committed to the long-term improvement of maintenance management. The distinction result between reactive and preventive planned maintenance (PPM) approach where the maintenance work planning program for preventive planned maintenance (PPM) approach drastically reduce errors in day-to-day operations, as well as increase the overall preparedness of plants in the case of an emergency.

Moreover, the maintenance approach also will affect the spare part management. Mostly, spare parts are not available at what time required for routine maintenance, down time is prolonged. If too many parts are kept by the management, the utility absorbs excessive costs and expenses due during the inventory (Vaisnys, Contri, Rieg \& Bieth, 2016). The maintenance engineer, reviews spare parts policies for plant equipment. This review is to ensure that the right parts are in stock in the right amounts stated by Wireman (2005).

Another aspect that related to maintenance approach is the type of maintenance work's contract, either it is conducted by in-house or apply outsource strategy which award the project to the third party. According to Ali and Mohammad (2009), it is found that world-class maintenance organisation will out-source 30 percent of their jobs. However, in the matter of contracting out, it is how well world-class maintenance companies manage the contracting out task and "how much" benefit they gain out of this activity. It does not depend on how much company's contract out. Yet, for the outsourcing strategy, it still depend on how well the maintenance organizations manage the contract and task as well as how much benefit they gain out by applying the outsourcing strategy. The factor of maintenance approach, spare part management and outsourcing maintenance works could be summarized as a technical aspect as it involves top management who responsible to setting up the overall maintenance approach as well as the organization has to deal with third party for outsourcing maintenance works. 
Policy deployment and organization is another recognized factor that influences the maintenance management effectiveness. This element encompasses written plan, policies, and procedures which define how the organisation will manage each specific component of facilities engineering maintenance services (Ali and Mohammad, 2009). As suggested by Wireman (2005) the maintenance organization should consider this factor as one of organizational business strategy in order to improve the overall performance. Nevertheless, the organization also needs to have an appropriate human resource and effective human resource management to run the business efficiently as well to ensure the optimum performance. Furthermore, pointed out that human resource management program is one of the successful factor of maintenance management as the organization must acquire the right person to manage, plan, supervise and execute the maintenance works. It is agreed by many authors stated by Wireman (2005) that effective maintenance of human resource management is one of the factors of a successful maintenance management program and staffing is an important part of any maintenance organization.

In order to support all the maintenance planning and execution, the allocation and control of budget play an important role in prompting the overall maintenance management. The elements that suggested by Wireman (2005) in relation to financial are maintenance budget control, cost of monitoring the contractor, and cost control for labor and material aspect. The organisation with excellent maintenance management will have lower variation between maintenance budget and maintenance cost, and the variance of maintenance cost should be investigated.

For the purpose of improvise the organizational performance in terms of maintenance management, all the strategy, policy and managerial aspect need to be assessed for the purpose of continuous improvement. This practice is being adopted in Malaysia public hospital as it part of requirement for quality management system with the purpose of obtaining the quality ISO certificate as well as gauge the effectiveness of current practice of maintenance management (Manaf, 2005). Most of the authors claimed that excellent maintenance performance organisations have a commitment in long-term improvement to maintenance practice and are constantly striving for better ways to do things (Weber and Thomas, 2005). The factors that lead to the continuous improvement of maintenance are the effective use of performance measurement, management commitment and the adoption of proactive maintenance. In conclusion, the factors of policy deployment and organization, human resource management, financial aspect and continuous improvement could be summarized as an administration and organizational factor as all the factors are under the control of top management.

\subsection{RESEARCH FRAMEWORK}

A useful Maintenance Key Performance Indicator (KPI) drives reliability growth while guiding your choices for improving maintenance effectiveness and efficiency. This can be represented in Table 1 and Figure 1.

Table 1 Key performance indicator as an independent variables

\begin{tabular}{|c|l|l|}
\hline No. & Elements & Items \\
\hline 1. & Monitoring and supervision & $\begin{array}{l}\text { Maintenance work complying standard specification, internal } \\
\text { audit International organization for standardization (ISO) }\end{array}$ \\
\hline 2. & Task planning and scheduling & Get a proper work, completed ppm and contingency plan \\
\hline 3. & $\begin{array}{l}\text { Computerized maintenance } \\
\text { management system } \\
\text { CMMS) }\end{array}$ & CMMS used, CMMS information sharing tool or CMIS \\
\hline 4. & Maintenance approach & Maintenance method, problem analysis (root cause analysis) \\
\hline 5. & Spare part management & $\begin{array}{l}\text { Spare part stock, cost value comparison, spare part stock } \\
\text { control }\end{array}$ \\
\hline 6. & Outsource strategy & Outsourcing vendor and third party \\
\hline 7. & $\begin{array}{l}\text { Policy deployment and } \\
\text { organisation }\end{array}$ & $\begin{array}{l}\text { Maintenance policy, application, policy review frequency, } \\
\text { policy review responsibility, maintenance responsibility, maintenance } \\
\text { organisation }\end{array}$ \\
\hline 8. & Human resources & $\begin{array}{l}\text { Human resource management, staff competency, continuous } \\
\text { training program, attend training, job scope and duty list, spirit } \\
\text { of working, staff performance, a total of balanced staff }\end{array}$ \\
\hline 9. & Financial & $\begin{array}{l}\text { Financial planning, annual budget, achievement of expenses, } \\
\text { analysis damage cost }\end{array}$ \\
\hline 10. & Continuous improvement & $\begin{array}{l}\text { Improvement implementation, improvement form, analysis } \\
\text { performance measurement, involvement of the upper } \\
\text { management, maintenance objective achievement }\end{array}$ \\
\hline
\end{tabular}

This study proposes three main components to be an indicator for effectiveness of maintenance management for the public hospital building, namely individual factors, maintenance aspects and administration and organizational factors. The individual factors consist of 3 factors such as monitoring and supervision, task planning and scheduling and computerized maintenance management system (CMMS). While maintenance aspects consider 3 factors following by maintenance approach, spare part management and outsource strategy. Meanwhile, administration and organizational factors contain 4 factors including human resources, financial and continuous improvement. 


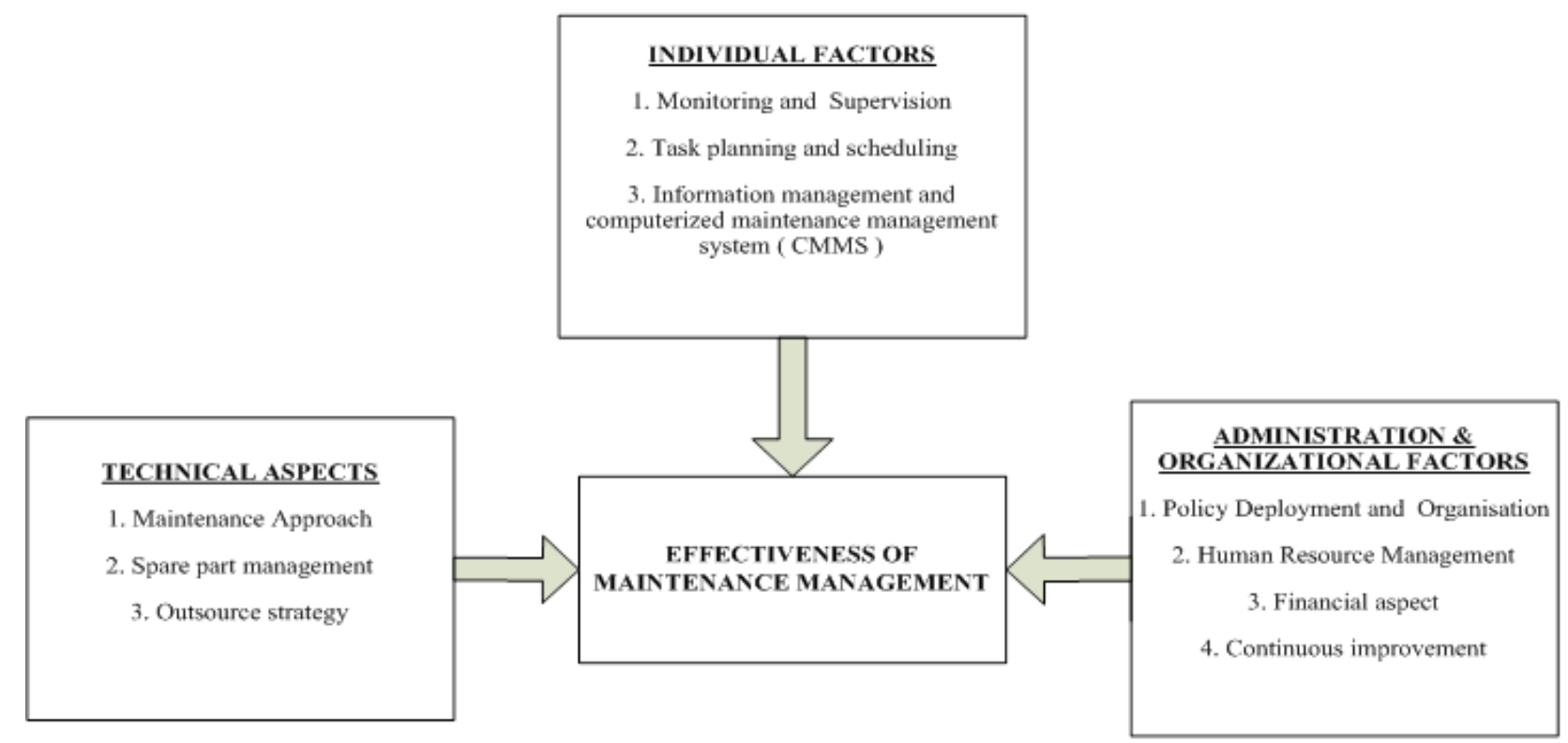

Figure 1 Maintenance performance measures: key performance indicators for effectiveness of maintenance management of public hospital building.

\subsection{METHODOLOGY}

\section{Research Design}

The research design is important as it serves as a blueprint for meeting the established research objective. Moreover, it helps researchers to arrive at the answer to research questions, whilst effectively controlling the variance, by means of providing logic that links the data to be collected to the initial research questions stated by Vaisnys, Contri, Rieg and Bieth (2016).

The quantitative research was adopted to evaluate the element in key performance indicator to measure the effectiveness of maintenance management. Primary data is obtained originally from the respondents for example an interviews, observations, action researches, case studies, and questionnaires. Therefore, a set of questionnaires used in this study is based on 5-point likert-scale, which 1 is strongly disagree and 5 is strongly agree. The results obtained from the survey are analyzed by performing descriptive analysis in SPSS

The secondary data are collected through previous researches such as journals, dissertations, related articles, books, websites, and magazines. This approach assist in clear understanding about the title and scope of the research. It also helps in constructing the questionnaires needed to achieving the research objectives.

\section{Research Instrument and Participants}

Key performance indicator for effectiveness of maintenance management were identified through literature reviews and preliminary survey. Close-ended questionnaires were drafted in five-point likert- scale and multiple choices based on the findings of literature and preliminary survey. The questionnaire consists of four sections, namely the respondent's background, hospital background, a key performance indicator of maintenance management effectiveness and successful maintenance management.

Overall, there are 32 public hospitals in northern region of peninsular Malaysia and maintenance manager for each hospital has been chosen to become as a respondent as they are involved in the overall stage of maintenance works and also responsible to monitor, supervise and reporting the maintenance works in the public hospital.

This study is a cross-sectional study where a set of questionnaires has been used as a medium to collect the related data in identifying the key performance indicators for effectiveness of maintenance management for the public hospital. Data collection for the current study was conducted based on self-administration method because it involved a short period of time, less expensive, gained quick answer and can clarify on the spot if there are any doubts from the respondents.

\subsection{RESULTS AND DISCUSSION}

This study proposes three main components to be an indicator for effectiveness of maintenance management for the public hospital building, namely individual factors, maintenance aspects and administration and organizational factors. Correlation analysis is used to describe the strength and direction of the linear relationship. In order to study the relationship between key performance indicators (KPI) for maintenance management and successful maintenance management, the spearman-correlation test was adopted. The spearmancorrelation is a non-parametric techniques. It is ideal to measured on nominal (categorical) and ordinal (ranked) scales. The significant on one - tailed used during analysis. It is useful when the data is small sample and data not meet the stringent assumption of the parametric techniques (Pallant, 2013). Therefore, for the purpose of data interpretation, this study adopted the value from (Cholasuke et al., 2004), a 
correlation value in the range of $0.4-0.7$ is considered moderate, a higher value (greater than 0.7 ) is considered to imply a strong correlation.

Table 2 shows the factors have scored in higher value is greater than 0.7 which indicates that the factors are moderate and perceived as a key performance indicators (KPI) of effectiveness of maintenance management for the public hospital building. The factor that notches the score is monitoring and supervision with the value of $F 1=.646$. This result demonstrates as moderate correlation is an effective maintenance strategy and this result proves that the monitoring and supervision on the maintenance works particularly for the outsource maintenance works for the public hospital is necessary and need to be performed efficiently in order to ensured the effectiveness of maintenance management.

Meanwhile, task planning and scheduling with scored the value of F2=.641. This factor significantly influenced the effectiveness of maintenance management as the maintenance work for the public hospital building involves technical complexity which the maintenance works need to be well-organized in order to elude any possibility for delay in completing the maintenance works. However, implement the effectiveness of maintenance management, maintenance manager responsible to provide schedule of preventive plan maintenance (PPM) to prevent the defect and failure from occurred. In addition, other factors that perceived as key performance indicator of effectiveness of maintenance management for the current study are information system and CMMS notched F3=.702. The adoption of technology software and hardware is needed in the modern world as it quicker and more effective which assists the organization to draw better alternative planning and result for the maintenance management.

The factor of maintenance approach has scored F4=.506 of value. This factor is the lowest value in maintenance aspect categories. Moreover, spare part management with the value F5=.513. This factor is less significant which indicate who do not realise the importance practice as a part of their business strategy. However, this factor cannot be mistreated because the spare part management can reduce the maintenance cost and saves time when the stocks of spare part available to used. In order to accomplished the maintenance work that required advanced equipment and the competent person so the outsourcing strategy was selected with the value F6=.625.

However, the strong correlation that perceived as a key performance indicators are policy deployment and organizational factor with the value F7=.796. Thus, this factor is highly recommended from respondent is best strategy for effectiveness of maintenance management to ensured the quality of maintenance work and reliability of equipment comply with the standard specification. The human resources with value $\mathrm{F} 8=.718$ in administration and organizational factors has also significant correlation because the selected maintenance staff required with capability to complete the maintenance work as per schedule and comply the standard specification. Meanwhile, financial aspect with value $\mathrm{F} 9=.726$ and continuous improvement with value $\mathrm{F} 10=.730$.

Therefore, based on the result the best categories in this study with strong correlation is administration and organizational factors compared individual factors and maintenance aspects. The result proved that the top management as an important in organization to approve the requirement especially in the financial and hiring the maintenance staff. Thus, value all the factors show greater than 0.7 that considered a strong correlation and that's show how important and significant the factors to successful maintenance management in public hospital building.

In order to ensure the mission and vision of the organization achieving, the top management will determine the direction of the organization for that period. This result revealed that the top management plays an important role in the maintenance management for the public building hospital. This fact is significant as the top management is in the top organizational hierarchy and holds the key in any organizational.

Table 2 Correlation between key performance indicators for effectiveness maintenance management and successful maintenance management

\begin{tabular}{|l|l|c|}
\hline & \multicolumn{1}{|c|}{ Parameters } & Value \\
\hline \multirow{4}{*}{ F1, Monitoring and supervision } & Spearman Correlation & .646 \\
\cline { 2 - 3 } & Sig. (1-tailed) & \\
\cline { 2 - 3 } \multirow{3}{*}{$\begin{array}{l}\text { F2, Task planning and } \\
\text { scheduling }\end{array}$} & Spearman Correlation & .641 \\
\cline { 2 - 3 } CMMS & Sig. (1-tailed) & .001 \\
\cline { 2 - 3 } & $\mathrm{N}$ & 32 \\
\hline \multirow{5}{*}{ F4, Maintenance approach } & Spearman Correlation & .702 \\
\cline { 2 - 3 } & Sig. (1-tailed) & .002 \\
\cline { 2 - 3 } & $\mathrm{N}$ & 32 \\
\cline { 2 - 3 } & Spearman Correlation & .506 \\
\cline { 2 - 3 } & Sig. (1-tailed) & .000 \\
\cline { 2 - 3 } & $\mathrm{N}$ & 32 \\
\hline F5, Spare part management & Spearman Correlation & .513 \\
\cline { 2 - 3 } & Sig. (1-tailed) & .001 \\
\cline { 2 - 3 } & $\mathrm{N}$ & 32 \\
\hline \multirow{5}{*}{ F6, Outsource strategy } & Spearman Correlation & .625 \\
\cline { 2 - 3 } & Sig. (1-tailed) & .000 \\
\hline
\end{tabular}

1:1 (2016) 1-8 | www.sainshumanika.utm.my | e-ISSN ISSN: 2289-6996 


\begin{tabular}{|l|l|c|}
\hline \multirow{3}{*}{$\begin{array}{l}\text { F7, Policy deployment and } \\
\text { organization }\end{array}$} & Spearman Correlation & 32 \\
\cline { 2 - 3 } & Sig. (1-tailed) & .796 \\
\cline { 2 - 3 } & $\mathrm{N}$ & .000 \\
\hline \multirow{5}{*}{ F8, Human resources } & Spearman Correlation & 32 \\
\cline { 2 - 3 } & Sig. (1-tailed) & .718 \\
\cline { 2 - 3 } & $\mathrm{N}$ & .000 \\
\hline \multirow{5}{*}{$*$} & Spearman Correlation & 32 \\
\cline { 2 - 3 } & Sig. (1-tailed) & .726 \\
\cline { 2 - 3 } & $\mathrm{N}$ & .000 \\
\hline F10, Continuous improvement & Spearman Correlation & 32 \\
\cline { 2 - 3 } & Sig. (1-tailed) & .730 \\
\cline { 2 - 3 } & $\mathrm{N}$ & .000 \\
\hline **. Correlation is significant at the 0.01 level (2-tailed). & 32 \\
\hline *. Correlation is significant at the 0.05 level (2-tailed). & \\
\hline
\end{tabular}

Notes: F1=Monitoring and supervision, F2=Task planning and scheduling, F3= Information system and CMMS, F4= Maintenance approach, F5= Spare part management, F6=Outsourcing strategy, F7=Policy deployment and organisation, F8=Human resources, F9= Financial aspects, F10= Continuous improvement

\subsection{CONCLUSION}

Maintenance management in the public hospital building is assume as critical component as a facility support services. An acceptable level of performance of the maintenance management of hospital building is simply unattainable without an effectiveness maintenance management support. This paper presents the key performance indicators as a measurement for effectiveness of maintenance management of public hospital building. A total ten factors, consisting of 70 variables were considered in the questionnaire. The analysis shows that the policy deployment and organization, human resources, financial aspects and continuous improvement have strong factors contribute to an effective maintenance management programme. The result implicates the needs of appointment the top management is important in maintenance organization to ensure the maintenance works efficiently. It was apparent from this research findings that the administration and organisation department play an important role to maintenance organization where has much effort to accomplish their roles and responsibilities towards successful implementation of building maintenance services. Other than that, Central maintenance management system (CMMS) also has a strong significant to effectiveness of maintenance management. Successful implementation of a project of this nature depends largely on commitment of organizations concerned towards realizing the objectives. This signifies that key performance indicators in administration and organization factors are strongly significant to key successful maintenance management and depend on the current condition during maintenance management processes and practices of the maintenance organization in public hospital building.

\section{References}

Adenuga, O.A. (2012). Maintenance Management Practices In Public Hospital Built Environment Nigeria Case Study. Journal Of Sustainable Development In Africa $14(1), 185-201$

Ahzahar, N.N.A., Karim, S.H. Hassan and Eman, J. (2011). A Study Of Contribution Factors To Building Failures And Defects In Construction Industry. The 2nd International Building Control Conferences.

Al-Arjani, A.H. (2002). Type And Size Of Project Influences On Number Of Bidders For Maintenance And Operation Projects In Saudi Arabia. International Journal of Project Management, 3(20), 279-87.

Ali, M. and Mohammad W. M. N. (2009). Audit assessment of the facilities maintenance management in a public hospital in Malaysia. Journal of Facilities Management 7(2), 142-158

Ali. Maisarah Ali, Wan. Mohammad. (2009). Audit Assessment Of The Facilities Maintenance Management In A Public Hospital In Malaysia. Journal of Facilities Management, (7) 2, 142-158

Cholasuke, C., Bhardwa R. and Antony, J. (2004). The Status Of Maintenance Management In UK Manufacturing Organizations Results From A Pilot Survey. Journal Of Quality In Maintenance Engineering, 10 (1), 5-15.

Irajpour, A., ANajafabadi, Mahbod M.A. and M. Karimi (2014). A Framework To Determine The Effectiveness Of Maintenance Strategies Lean Thinking Approach Mathematical Problems In Engineering, 1-11.

Manaf, N.H.A. (2005). Quality Management In Malaysian Public Health Care. International Journal of Health Care Quality Assurance, 18(3), 204-216.

Mydin, O.M.A. (2014): Assessment Of Significant Causes To School Building Defects, E3S Web of Conferences 301002.

Shohet, I.M. (2002). Key Performance Indicators For Maintenance Of Health-Care Facilities. CIB W070 2002 Global Symposium, 79-90.

Vaisnys P., Contri, P., Rieg C. and M. Bieth. (2016). Monitoring The Effectiveness Of Maintenance Programs Through The Use Of Performance Indicators Summary Report.

Weber A. and Thomas R. (2005). Key Performance Indicators - Measuring And Managing The Maintenance IAVARA Work Smart, 1-16.

Wireman, T. (2005). Developing Performance Indicators For Managing Maintenance. Industrial Press, Inc., and New York, NY. Developing Performance Indicators for Managing Maintenance, 1-36. 